OPEN ACCESS

Edited by:

Yibei Zhu,

Soochow University, China

Reviewed by:

Wei Chen,

Stanford University, United States

Tiziana Schioppa,

University of Brescia, Italy

${ }^{*}$ Correspondence:

Haihong Zhang

zhanghh@jlu.edu.cn

Xianghui Yu

xianghui@j/u.edu.cn

Specialty section: This article was submitted to

Cancer Immunity and Immunotherapy, a section of the journal

Frontiers in Oncology

Received: 03 August 2021 Accepted: 16 November 2021 Published: 07 December 2021

Citation:

Liu C, Cong X, Wang Y, Guo Q, Xie Y,

Geng F, Guo J, Dong L, Zhou Y, Wu H,

Yu B, Wu J, Zhang H, Yu X and Kong $W$ (2021) Fast DNA Vaccination

Strategy Elicits a Stronger Immune Response Dependent on $C D 8^{+} \mathrm{CD} 11 \mathrm{C}^{+}$Cell Accumulation. Front. Oncol. 11:752444. doi: 10.3389/fonc.2021.752444

\section{Fast DNA Vaccination Strategy Elicits a Stronger Immune Response Dependent on $\mathrm{CD}^{+}{ }^{+} \mathrm{CD} 11 \mathrm{c}^{+}$Cell Accumulation}

\author{
Chenlu Liu 1,2,3, Xianling Cong ${ }^{2}$, Yuqian Wang ${ }^{2}$, Qianqian Guo ${ }^{1,3}$, Yu Xie ${ }^{1,3}$, Fei Geng ${ }^{1,3}$, \\ Jie Guo ${ }^{1,3}$, Ling Dong ${ }^{1,3}$, Yi Zhou ${ }^{1,3}$, Hui $W^{1,3}$, Bin $Y^{1,3}$, Jiaxin $W u^{1,3}$, \\ Haihong Zhang ${ }^{1,3^{*}}$, Xianghui $\mathrm{Yu}^{1,3^{*}}$ and Wei Kong ${ }^{1,3}$ \\ ${ }^{1}$ National Engineering Laboratory for AIDS Vaccine, College of Life Science, Jilin University, Changchun, China, \\ ${ }^{2}$ Biobank, China-Japan Union Hospital of Jilin University, Jilin University, Changchun, China, ${ }^{3}$ Key Laboratory for Molecular \\ Enzymology and Engineering, College of Life Science, Jilin University, Changchun, China
}

Conventional DNA vaccine strategies usually employ a regimen of immunizations at 2week or longer intervals to induce effective memory cell-dependent immune responses. Clinical cancer treatment requires a faster immunization strategy to contend with tumor progression. In this study, a novel fast immunization strategy was established, wherein a DNA vaccine was intramuscularly administered on days 0,2 , and 5 in a murine lung cancer model. Effector cells peaked 7 to 10 days after the last vaccination. Compared with traditional 2-week-interval immunization strategies, antigen-specific cytolysis and INF- $\gamma$ secretion were significantly enhanced under the fast vaccination approach. As a result, the rapidly administered DNA vaccine elicited stronger and more prompt antitumor effects. The probable underlying mechanism of fast immunization was the accumulation of $\mathrm{CD} 8{ }^{+} \mathrm{CD} 11 \mathrm{C}^{+}$antigen-presenting cells at the injection site, which enhanced subsequent antigen presentation. In conclusion, the fast DNA vaccination strategy shortened vaccination time to 5 days and elicited a stronger antitumor immune response.

Keywords: DNA vaccine, short-interval vaccination strategy, antigen-presenting cells, chemokines, lung cancer

\section{INTRODUCTION}

DNA vaccines are a promising cancer immunotherapeutic strategy, offering advantages such as a favorable safety profile, and simple preparation and storage requirements $(1,2)$. Additionally, DNA vaccine also has an advantage in inducing $\mathrm{CD}^{+}$and $\mathrm{CD} 4^{+} \mathrm{T}$ cell response, which is responsible for the clearance of tumor cells (3). However, given the insufficient immunity induced by a single dose of DNA vaccines, immunization requires the administration of several doses. In the current vaccination strategies, an interval of at least 2 weeks is recommended between doses, thus requiring at least a month or more for the generation of a robust immune response (4-6). Therefore, immune

Abbreviations: APC, antigen-presenting cell; DC, dendritic cell; rAd, recombinant adenovirus; qRT-PCR, quantitative realtime PCR; CTL, cytotoxic T lymphocyte; CFSE, carboxyfluorescein diacetate succinimidyl ester; FACS, flow cytometry; MDSCs, myeloid-derived suppressor cells; iDC, immature DC; mDC, mature DC. 
response induction via DNA vaccine therapy is generally considered time-consuming $(7,8)$. This slow process struggles to effectively counteract rapid cancer progression (9). To date, a fast DNA vaccination strategy that can efficiently elicit immune responses has not been established.

Recently, a personalized poly-epitope DNA vaccine of Washington University School of Medicine is in Phage I clinical trials among triple-negative breast cancers (NCT02348320). According to statistics in ClinicalTrial.gov, accumulating cancer DNA vaccines are in Phage I or II clinical trials (such as NCT02204098, NCT04090528, and NCT03600350). DNA vaccine has developed in many fields. The antigens have changed from traditional tumor-specific antigens or tumor-associating antigens to neoantigens (NCT03122106) (10). The delivery system has also developed to enhance the immunogenicity. Gene gun, electroporation, Tattoo, and many other devices are applied in DNA vaccine $(7,11)$. However, most of DNA vaccines are still vaccinated with several-week intervals. The vaccination strategy may be the limitation of DNA vaccine in the future. Most cancer vaccines, with the exception of those targeting virus-induced tumors, are designed as therapeutic vaccines (12-14). Prophylactic vaccine employs this strategy and is vaccinated with 2 or more-week intervals. Memory B or T cells could be generated after several vaccinations and protect hosts from being infected $(8,9,15)$. This process of memory cell generation is time-consuming. When it is applied in therapeutic cancer vaccine, this strategy showed insufficient. A single dose of DNA vaccine could not induce strong enough antigen-specific effector cells or memory lymphocytes to control the rapid cancer progression (16). The rapid nature of cancer progression highlights the need for more expeditious strategies for therapeutic cancer vaccination.

Schumacher and colleagues previously reported a fast DNA vaccination strategy, wherein vaccines were administered three times in 1 week and elicited a stronger immune response due to prolonged antigen expression in subcutaneous tissue. However, in this strategy, the vaccines were to be administered intradermally, as no enhanced effects were observed after intramuscular injection (7). Administration route-associated restrictions may thus limit the application and promotion of fast vaccination strategies.

Intramuscular injection is most frequently used for DNA vaccine administration (17-19). While various muscle cells express antigens encoded by the administered DNA, a lack of antigen-presenting cells (APCs), such as dendritic cells (DCs), has been reported at the site of intramuscular injections $(20,21)$. Thus, enhancing APC infiltration into the muscle injection site may be an effective method for the rapid induction of a potent immune response $(21,22)$.

$\mathrm{CD} 11 \mathrm{c}$ is a transmembrane integrin alpha $\mathrm{X}$ chain protein highly expressed on DCs, most monocytes/macrophages, some B cells, and natural killer cells. In peripheral muscle tissue, DCs and macrophages-both APCs-express CD11c. DCs are the major APCs for $\mathrm{T}$ lymphocyte activation $(23,24)$. The crosspresentation of antigens encoded by DNA vaccines is critical for the induction $\mathrm{CD}^{+} \mathrm{T}$ cell immunity $(24,25)$. The migration of APCs to the inflamed vaccine injection site is facilitated by chemokines $(26,27)$. Depending on the vaccine adjuvant, DCs could be found to accumulate at the muscle injection site (2830 ). In the current study, we sought to determine whether the DNA vaccine-induced immune response could be potentiated by increasing APC recruitment to the injection site. Hence, we analyzed the expression of chemokines and the abundance of APCs at the site of injection after vaccination. Based on the timing of APC migration, we designed a fast vaccination strategy. We used the well-studied CpDV-IL2-sPD1/MS DNA vaccine, which encodes two tumor antigens, MUC1 (M) and survivin (S), and included soluble PD1, CpG motif, and IL-2 as immunoadjuvants to enhance the $\mathrm{CD}^{+} \mathrm{T}$ cell-mediated antitumor immune response. Genes of MUC1 and survivin (MS) were fused to express in vaccine. Soluble PD1 (sPD1) interacts with PD-L1 on the surface of DCs to improve antigen uptake and presentation. CpG is a TLR9 agonist, and IL-2 is a major Th1 cytokine; both molecules play an important role in lymphocyte activation, as demonstrated in our previous research $(31,32)$.

$\mathrm{CD}^{+}$effector $\mathrm{T}$ cells are the mainly executors of killing tumor cells. Hence, to induce a strong enough immune response as soon as possible will improve the antitumor (16). Therefore, we hypothesize that fast vaccination strategies should perform better than currently applied DNA vaccine administration regimens. In this study, we compared the antitumor efficacy of fast DNA vaccination with that of conventional strategies and sought to elucidate the molecular mechanism underlying the efficacy of the fast vaccination approach. We postulated that a fast vaccination strategy would allow for the recruitment of APCs to the injection site. In order to further enhance the immune response and antitumor effect of fast immunization using a DNA vaccine, we use the DNA primed-recombinant adenovirus ( $\mathrm{rAd}$ ) vaccine boost strategy, which was demonstrated to be an effective antitumor strategy in our previous study (33). The current findings highlight the potential of a novel fast DNA vaccination strategy that merits further evaluation in preclinical and clinical research.

\section{MATERIALS AND METHODS}

\section{Mice}

Experiments with $\mathrm{C} 57 \mathrm{BL} / 6$ and $\mathrm{BALB} / \mathrm{c}$ mice (Beijing Huafukang Biology Technology Co., Ltd., China) were approved by the Ethical Committee for the Use of Laboratory Animals at Jilin University and were carried out in strict accordance with the National Institutes of Health Guide for the Care and Use of Laboratory Animals. Mice were female, 6 to 8 weeks old.

\section{Cell Line}

Mouse colorectal cancer cell line CT26 was preserved at the National Engineering Laboratory for AIDS Vaccine of Jilin University. Mouse lung cancer cell line Lewis (No.: GF123) was purchased from Shanghai Gefan Biotechnology Co., Ltd. Lewis-GFP-MS and CT26-GFP-MS cell lines stably expressing 
tumor antigens MUC1 and survivin were previously generated in our laboratory (31).

\section{Plasmid and Virus Sample Processing}

The DNA vaccine CpDV-IL2-sPD1/MS and rAd, Ad-MS, were previously constructed $(31,33)$. DNA vaccine plasmids were amplified and purified by Changchun BCHT Biotechnology Co. The rAd vaccine was manufactured by Shenzhen Yuanxing Gene Technology Co., Ltd., and contained $2 \times 10^{11} \mathrm{vp} / \mathrm{ml}$. Both vaccines were diluted to the final concentration in PBS (phosphate-buffered saline) buffer.

\section{Immunization and Tumor Challenge}

Two immunization strategies were used in this research based on vaccination intervals, namely, a traditional immune strategy (normal immunization strategy) with 1- or 2-week intervals, and a fast immunization strategy (days 0-2-5) with 2-day and 3day intervals. Both DNA and rAd vaccines were administered intramuscularly. DNA vaccine is vaccinated at a dosage of $100 \mu \mathrm{g}$ or a triple dosage.

For tumor inoculation, C57BL/6 mice were subcutaneously injected with $1.3 \sim 1.4 \times 10^{5}$ Lewis-GFP-MS cells in the right hind flank, and the day of inoculation was recorded as day 0 . In the normal immunization strategy group, the DNA vaccine was administered on day 1 . In the fast immunization group, the DNA vaccine was administered when the tumor reached approximately $50 \sim 100 \mathrm{~mm}^{3}$, which occurred between day 4 and day 8. Tumor size was measured using a caliper, and the tumor volume was calculated $\left(1 / 2\right.$ length $\times$ width $\left.^{2}\right)$. The average volume in control group mice on the day of treatment initiation was set to a value of $100 \%(34,35)$. Tumor-bearing mice were euthanized when the maximum diameter measured over $1.5 \mathrm{~cm}$.

\section{Quantitative Real-Time PCR}

Total RNA of muscle or inguinal lymph nodes samples was isolated using TRIzol reagent (Invitrogen). cDNA was synthesized, and qRT-PCR was then performed to analyze the expression of chemokine genes as previously described. The quantitative real-time PCR (qRT-PCR) primer sequences were as follows: $\beta$-actin forward $5^{\prime}$-CAAGCAGGAGTACGACGAGT$3^{\prime}$, reverse 5'-GGCTGGCATGAGGTGTGTA-3'; Ccl3 forward 5' CCTCTGTCACCTGCTCAACA-3', reverse 5'-GATGAATTGG CGTGGAATCT-3'; Ccl4 forward 5'-CCCACTTCCTGCTGTTT CTC-3', reverse 5'-GAGGAGGCCTCTCCTGAAGT-3'; Ccl5 forward 5'-TGCCCACGTCAAGGAGTATTTC-3', reverse 5' AACCCACTTCTTCTCTGGG TTG-3'; Ccl19 forward 5'-CACT CACTCTCTGTGGCCT-3', reverse 5'-GGGCCAGAGTGATT CACATC-3'; Ccl20 forward 5'-TGCTCTTCCTTGCTTTG GCATGGGTA-3', reverse $5^{\prime}$-TCTGTGCAGTGATGTGCAGG TGAAGC-3'; and Ccl21 forward 5'-TACTGGGCTATCC

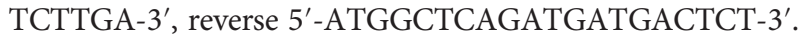

\section{Preparation of Cell Suspensions From Spleen, Muscle, and Tumor Tissues}

The spleen was dissected, washed with sterile PBS buffer, cut into pieces, ground, and filtered with gauze twice to remove connective tissue. Red blood cells were removed using red blood cell lysis buffer (ACK, BioLegend, San Diego, CA, USA). Cellular debris were removed via centrifugation. The concentration of splenocyte suspensions was adjusted to $1 \times$ $10^{7}$ cells $/ \mathrm{ml}$.

Tumor or muscle cell suspensions were prepared in a similar manner. However, prior to tissue grinding, tumor or muscle tissues were cut into pieces and incubated with collagenase I (final concentration: $40 \mu \mathrm{g} / \mathrm{ml}$, Roche, Basel, Switzerland) for $2 \mathrm{~h}$ at $37^{\circ} \mathrm{C}$ and $5 \% \mathrm{CO}_{2}$. The tumor tissues were subjected to the same procedures as described for splenocyte suspensions.

\section{IFN- $\gamma$ Secretion}

IFN- $\gamma$ released by splenocytes following MUC1- and survivinspecific stimulation was detected using an ELISpot kit as previously described. The peptide mixture, including survivin $\left(\mathrm{H} 2-\mathrm{K}^{\mathrm{d}}\right.$ sequence for BALB/c mice: AFLSVKKQF and $\mathrm{H} 2-\mathrm{D}^{\mathrm{b}}$ sequence for C57BL/6 mice: STFKNWPFL, final concentration: $10 \mu \mathrm{g} / \mathrm{ml})$ and MUC1 $\left(\mathrm{H} 2-\mathrm{K}^{\mathrm{d}}\right.$ sequence: APDTRPAPG and $\mathrm{H} 2$ $\mathrm{D}^{\mathrm{b}}$ sequence: SAPDTRPAP, final concentration: $\left.10 \mu \mathrm{g} / \mathrm{ml}\right)$, was used to stimulate splenocytes.

\section{Cytotoxic T Lymphocyte Assay}

We used carboxyfluorescein diacetate succinimidyl ester (CFSE) staining to evaluate splenocyte cytotoxicity. Lewis-GFP-MS cells and wild-type Lewis cells were stained with high $(5 \mu \mathrm{M})$ and low $(0.5 \mu \mathrm{M})$ concentrations of CFSE. Splenocytes from C57BL/6 mice and the target Lewis-GFP-MS/Lewis cells were incubated at different effector-to-target (E:T) ratios for $8 \sim 10 \mathrm{~h}$ at $37^{\circ} \mathrm{C}$ and $5 \%$ $\mathrm{CO}_{2}$, followed by analysis of dead target cell percentage among Lewis-GFP-MS cell and wild-type Lewis cell populations using a FACS Caliber instrument (BD Biosciences). Splenocytes from $\mathrm{BALB} / \mathrm{c}$ mice were incubated with CT26-GFP-MS/CT26 treated with CFSE as described above. Lewis-GFP-MS/Lewis or CT26GFP-MS/CT26 was determined by the strains of mice. Cytotoxicity activity was detected by flow cytometry, and specific lysis was calculated as follows: specific lysis $(\%)=[1-$ (peptide-loaded cells/unloaded cells from the experiment group)/(peptide-loaded cells/unloaded cells from target cell control group)] $\times 100(36,37)$.

\section{Isolation of CD11c ${ }^{+}$Cells}

$\mathrm{CD}_{11 \mathrm{c}^{+}}$cells were isolated from different tissues using the CD11c MicroBeads UltraPure mouse kit (Miltenyi Biotec, Order no. 130-108-338) with an LS-positive selection column, as per the manufacturer's instructions. Muscle tissues were cut into pieces and incubated with collagenase for $2 \mathrm{~h}$ at $37^{\circ} \mathrm{C}$ and $5 \%$ $\mathrm{CO}_{2}$. A total of $10^{8}$ cells were resuspended in $400 \mu \mathrm{l}$ buffer. CD11c Microbeads UltraPure $(100 \mu \mathrm{l})$ were then added and incubated for $10 \mathrm{~min}$ in the dark at $2^{\circ} \mathrm{C}-8^{\circ} \mathrm{C}$, followed by separation using the appropriate columns.

\section{Flow Cytometry (FACS)}

The frequency of different immune cell types was determined using FACS. Myeloid-derived suppressor cells (MDSCs) in tumor or spleen tissue were analyzed using a mouse MDSC Flow 
Cocktail 1 (CD11b PE/Gr-1 APC/Ly-6G FITC, BioLegend). Regulatory $\mathrm{T}$ cells were analyzed using the Mouse Regulatory $\mathrm{T}$ Cell Staining Kit \#1 (eBioscience). FITC anti-mouse CD8 $\alpha$ antibody (clone: 53-6.7, BioLegend), APC anti-mouse CCR5 antibody (clone: HM-CCR5, BioLegend), PE anti-mouse CCR6 antibody (clone: 29-2L17, BioLegend), and PE/Cy7 antimouse CCR7 antibody (clone: 4B12, BioLegend) were used to

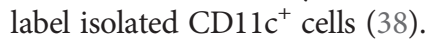

\section{Statistical Analysis}

All statistical analyses were performed with GraphPad Prism software (version 7.0, GraphPad, Inc., La Jolla, CA, USA) using unpaired t-tests and One-way ANOVA, as previously described.

\section{RESULTS}

\section{Upregulation of Chemokines at the Injection Site and Ipsilateral Inguinal Lymph Nodes After DNA Vaccination}

APC migration is driven by chemokines. To define which specific chemokines were upregulated after the first vaccination, we analyzed chemokine mRNA expression. The upregulation of a series of chemokines was observed in muscle or the ipsilateral inguinal lymph nodes throughout $0-168 \mathrm{~h}$ (time points: $0,3,6,9$, $12,24,48,72,96$, and $168 \mathrm{~h}$ ) after DNA vaccine administration (Figure 1A). The mRNA levels of $\mathrm{Ccl} 3 / \mathrm{Ccl} / \mathrm{Ccl} 5 / \mathrm{Ccl} 20$ (recruiting immature DCs, iDCs) and $\mathrm{Ccl}$ 19/Ccl 21 (recruiting mature DCs, mDCs) were determined (Figure 1). At the injection site, $\mathrm{Ccl} 3$ was upregulated approximately 3.88 4.11-

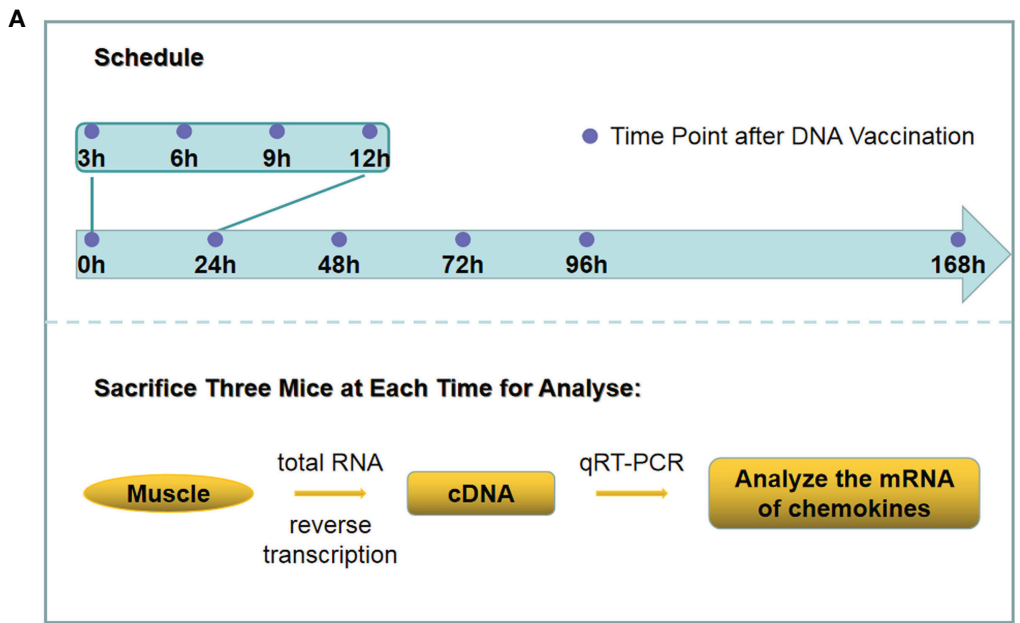

B

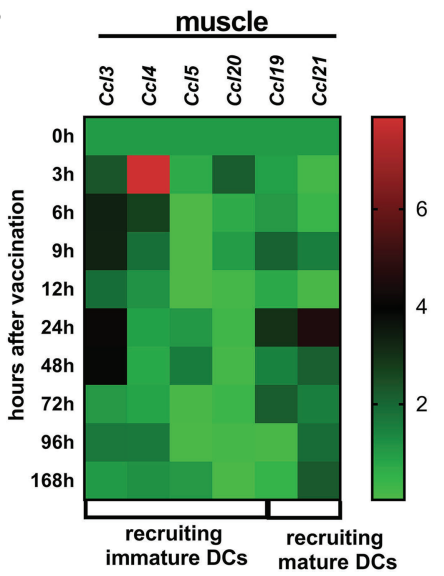

C

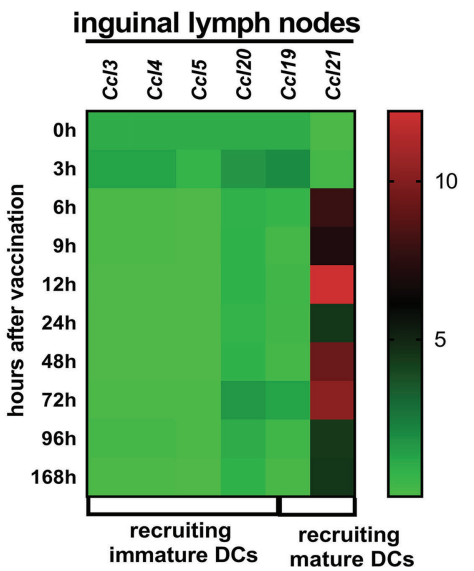

FIGURE 1 | Chemokines within muscle at the injection site and ipsilateral lymph nodes. (A) Administration and treatment schedule. Twenty-seven BALB/c mice were vaccinated with $100 \mu \mathrm{g}$ CpDV-IL2-sPD1/MS DNA vaccine intramuscularly in hindlimb skeletal muscle. At 0, 3, 6, 9, 12, 48, 72, 96, and 120 h after the injection, three mice were sacrificed, and the muscle at the injection site and the inguinal lymph nodes were dissected. Total RNA was extracted and reversetranscribed to cDNA. Quantitative real-time PCR (qRT-PCR) was conducted to analyze chemokine mRNA levels. The relative mRNA levels of chemokines recruiting immature dendritic cells (DCs) (Cc/3, Cc/4, Cc/5, and Cc/20) and those recruiting mature DCs (Cc/19 and Cc/21) in muscle at the injection site (B) and ipsilateral lymph nodes (C). 
fold during $24 \sim 48$ h post-vaccination, Ccl5 expression increased 1.57 -fold at $48 \mathrm{~h}$ post-vaccination, and Ccl4 temporarily increased about 8 -fold at $3 \mathrm{~h}$ post-vaccination (Figure 1B). Ccl19 increased 4.56-fold at $24 \mathrm{~h}$, while Ccl21 increased 2.14 4.56 fold during 24 48 h (Figure 1B). When APCs uptake antigen at the injection site, they could carry the vaccine or antigen to lymph node acting the call for CCL19 or CCL21 $(15,26,27)$. Hence, these chemokines mRNA were also analyzed in lymph nodes. Within the ipsilateral inguinal lymph nodes, of iDC-recruiting chemokines $\mathrm{Ccl} 3 / \mathrm{Ccl} 4 / \mathrm{Ccl} 5 / \mathrm{Ccl} 20$, only Ccl20 exhibited a modest 1.294 -fold increase at the 72 -h time point, while low expression was observed for the rest (Figure 1C). mDC-recruiting Ccl21 was considerably upregulated 12.21-fold at the 9-h point, 9.30-fold at the 48-h point, 10.24 -fold at the 72 -h point, and 4.38 -fold at the $96-\mathrm{h}$ point (Figure 1C). These results suggested that local proinflammatory chemokines were upregulated at the injection site after DNA vaccination, which could enhance the recruitment of APCs, particularly DCs, and Ccl21 began to be upregulated in lymph nodes since $24 \mathrm{~h}$ later DNA vaccination.

\section{Migration of CD11c ${ }^{+}$APCs Into the Injection Site and Homing to Ipsilateral Inguinal Lymph Nodes}

CCR5 is the receptor of CCL3, CCL4, and CCL5, CCR6 is the receptor of CCL20, and CCR7 is the receptor of CCL19 and CCL20 (39). CCR5 and CCR6 could express on immature DCs and macrophage, interact with CCL3, CCL4, CCL5, and CCL20, and migrate APCs to the inflammatory site, including DNA vaccine injection site. When APCs internalize the vaccine, APCs downregulate CCR5 and CCR6, upregulate CCR7, and chemotactically migrate to lymph nodes by CCL19 and CCL21. Antigen presentation by APCs is a key process for immune response induction. CD11c is a prevalent APC marker $(40,41)$. To validate whether chemokines could recruit APCs into the

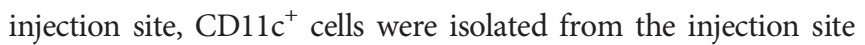
and ipsilateral inguinal lymph nodes at different time points after the first or second vaccination and analyzed via FACS. BALB/c mice were divided into four groups, and the immunization process is shown in Figure 2A. Two days after the first vaccination, we observed a nearly twofold increase of $\mathrm{CD} 8^{+} \mathrm{CD} 11 \mathrm{c}^{+}$cell accumulation at the injection site. Five days post-vaccination, the number of $\mathrm{CD} 8^{+} \mathrm{CD} 11 \mathrm{c}^{+}$cells decreased back to that of the PBS group. Upon the second vaccination 2 days after the first, $\mathrm{CD}^{+} \mathrm{CD} 11 \mathrm{c}^{+}$cells accumulated back to previously observed levels after 3 days (Figure 2B). These results indicated that $\mathrm{CD} 11 \mathrm{c}^{+}$ APCs were recruited to the injection site post-vaccination.

Chemokine receptor expression was also analyzed to determine $\mathrm{CD} 11 \mathrm{c}^{+}$cell migration. $\mathrm{CD}^{+} \mathrm{CCR} 5^{+} \mathrm{CD} 11 \mathrm{c}^{+}$cells, responding to CCL3, CCL5, and CCL20, exhibited a similar migration pattern to that of $\mathrm{CD}^{+} \mathrm{CD} 11 \mathrm{c}^{+}$cells and were significantly recruited to the injection site post-vaccination $(p<0.05)$ (Figure 2C). $\mathrm{CD}^{+} \mathrm{CCR} 6{ }^{+} \mathrm{CD} 11 \mathrm{c}^{+}$cells, also responding to CCL3, CCL5, and CCL20, were observed at the injection site after the second vaccination $(p<0.05)$ (Figure 2D). In addition, $\mathrm{CCR}^{+}$cells responding to CCL21, a marker of
mDCs, exhibited a modest increase $(p>0.05) 2$ days after the first vaccination, but no significant differences were observed between the four groups (Figure $2 \mathbf{E}$ ).

$\mathrm{CD}_{11 \mathrm{c}^{+}}$cells migrated away from the injection site 5 days after the last vaccination in each group. Thereafter, we investigated whether these cells were attracted to the ipsilateral inguinal gland of the injection site. However, only $\mathrm{CD} 8^{+} \mathrm{CD} 11 \mathrm{c}^{+}$ cells appeared significantly increased two days after first injections $(p<0.05)$ (Figure 2F). iDCs expressing CCR5 or CCR6 exhibited a decline in ipsilateral inguinal gland (Figures 2G, H). No change was observed for $\mathrm{CCR} 7^{+} \mathrm{CD} 11 \mathrm{c}^{+}$ mDCs (Figure 2I).

Data in Figure 2 indicate that $\mathrm{CD}_{11} \mathrm{c}^{+}$APCs may accumulate at the injection site 2 days after the first vaccination as well as after the administration of booster vaccines.

\section{Fast DNA Vaccination Elicited Stronger Immune Responses}

Based on the timing of $\mathrm{CD} 11 \mathrm{c}^{+}$cell accumulation at the injection site (Figures 1, 2), we speculated that vaccination at days 0,2 , and 5 would induce a more rapid and pronounced immune response. To assess this, healthy $\mathrm{BALB} / \mathrm{c}$ mice were divided into three groups and vaccinated following fast or conventional strategies and sacrificed to then evaluate antitumor immune responses (Figure 3A). According to our previous results, administration of DNA vaccine CpDV-IL2-sPD1/MS under the normal immunization strategy could only induce a modest immune response. Further, rAd could boost this immune response. Thus, we questioned whether the rAd boost could further enhance the immune response under fast vaccination. Hence, for this experiment, both normal and fast DNA vaccination were boosted with 2 -week-interval rAd vaccination. To analyze the antigen-specific cytolysis ability of splenocytes (effector cells), cancer cells CT26 with or without antigens (targets cells) labeled with different concentrations of CFSE were co-incubated with splenocytes with a ratio (effector cells: targets cells) of 50:1 or 100:1. FACS was used to detect the antigen-specific lysis. Cytotoxic $\mathrm{T}$ lymphocyte (CTL) assay results revealed that splenocytes from the fast vaccination group killed 50\% more tumor cells than those of the normal vaccination group $(p<0.01$, Figure 3B). Further, the secretion of IFN- $\gamma$ was $4 \sim 5$-fold greater in the fast vaccination group compared with that in the normal vaccination group $(p<0.001$, Figure 3C).

\section{The DNA Vaccine-Induced Antigen Accumulation at the Injection Site Did Not Enhance Immune Response Under Fast Vaccination}

We designed the fast vaccination strategy based on the timing of APC migration. Fast vaccination induced a stronger immune response than normal vaccination (Figure 3). Moreover, as short-interval vaccination may cause prolonged antigen expression at the injection site, we questioned whether the fast vaccination strategy could also enhance the immune response via the accumulation of DNA vaccine-encoded antigens at the injection site. 
A

\begin{tabular}{|l|l|}
\hline Group 1 \\
PBS
\end{tabular}

First DNA Vaccination (i.m.) : CpDV-IL2-sPD1/MS, 50 $\mu$ g each hind leg.

$\square$ Second DNA Vaccination (i.m.) : two days after first vaccination.

- PBS (i.m.) : 50ug each hind leg.

- Sacrifice for FCM analysis.

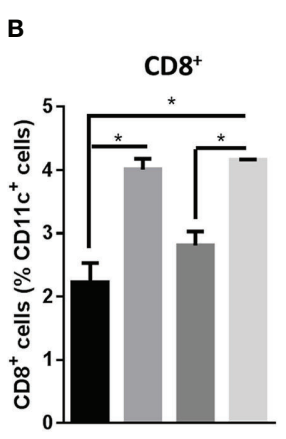

C

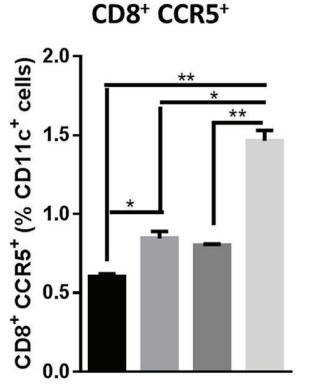

D

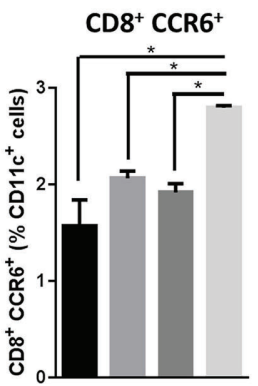

$\mathbf{H}$

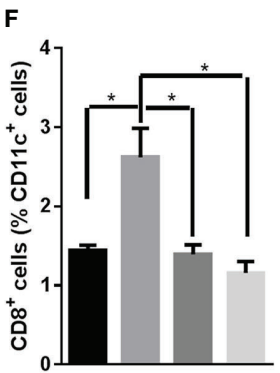

G

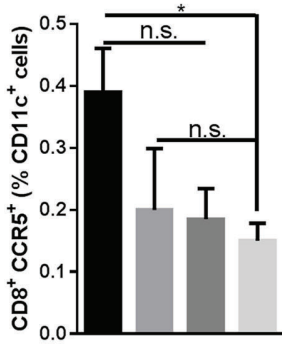

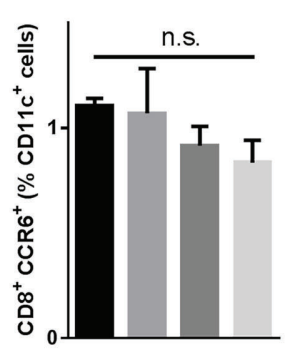

'
E
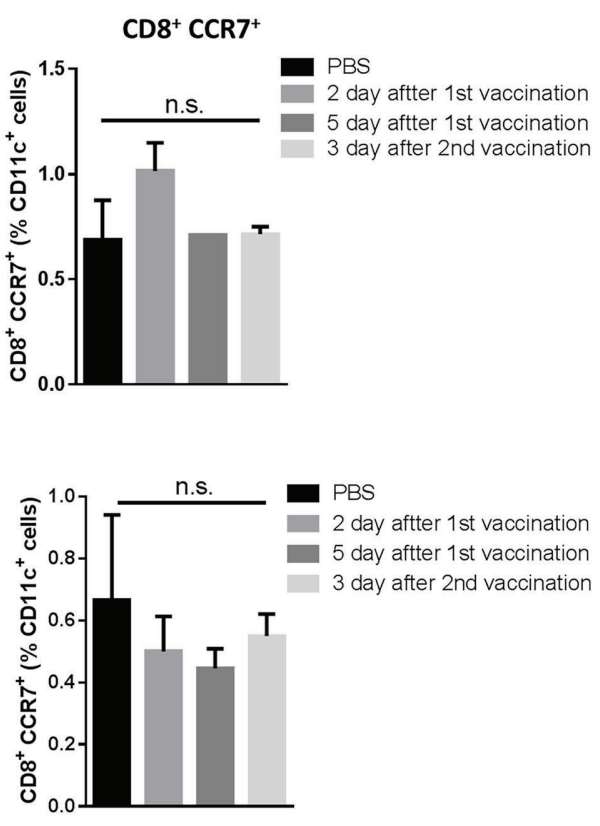

Lymph node

FIGURE 2 | Timeline of $\mathrm{CD}_{11 \mathrm{C}^{+}}$antigen-presenting cell (APC) migration to the injection site and homing to ipsilateral inguinal lymph nodes. (A) Four groups of $\mathrm{BALB} / \mathrm{c}$ mice (three mice in each group) were vaccinated as indicated, and $100 \mu \mathrm{g}$ CpDV-IL2-sPD1/MS was injected intramuscularly at each time point. All mice were sacrificed on the same day. CD11 $\mathrm{c}^{+}$cells were isolated and analyzed via flow cytometry. Percentages of $\mathrm{CD} 8^{+}, \mathrm{CD} 8^{+} / \mathrm{CCR} 5^{+}, \mathrm{CD}^{+} / \mathrm{CCR} 6^{+}$, and $\mathrm{CD} 8^{+} / \mathrm{CCR} 7^{+}$ subsets among CD11 ${ }^{+}$cells isolated and enriched from muscle cells $(\mathbf{B}-\mathbf{E})$ and lymph nodes $(\mathbf{F}-\mathbf{I}) .\left({ }^{*} p<0.05,{ }^{* *} p<0.01, n . s ., p>0.05\right)$.

To verify this conjecture, $\mathrm{BALB} / \mathrm{c}$ mice were separated into a normal-dosage group, wherein mice were vaccinated using the fast vaccination strategy, and a triple-dosage group (Figure 4A). We employed CTL assay to analyze the antigen-specific cytolysis ability of splenocytes. At the 100:1 ratio of E:T, cytolysis of the fast vaccination group $(11.83 \%)$ is higher than that of the triple-dose group $(7.88 \%, p<0.01)$ and that of the control group $(5.61 \%$, $p<0.001)$. At 50:1 and 25:1 ratios, they have the same trend with the 100:1 ratio (Figure 4B). In ELISpot assay, splenocytes in the fast vaccination group secreted almost two-fold IFN- $\gamma$ (353.5) of splenocytes in the triple-dose group (186) ( $p<0.01$, Figure 4C).
According to CTL and ELISpot assay results, DNA vaccine administration under the fast immunization strategy elicited a stronger immune response than did the triple-dosage strategy $(p<$ 0.01) (Figures $4 \mathrm{~B}, \mathrm{C}$ ). The percentages of $\mathrm{CD} 9^{+}$in $\mathrm{CD} 8^{+}$cells and MDSCs (immunosuppressive cells) among splenocytes indicated that triple dosage increased MDSCs and decreased effector cells $(p<0.001)$ (Figures 4D, E). Further, triple dosage did not enhance the immune response and induced immune suppression instead. Thus, we aimed to confirm whether the amount of antigen was indeed associated with immune responses. Hence, the DNA vaccine dosage was reduced to 50 or $25 \mu \mathrm{g}$, 

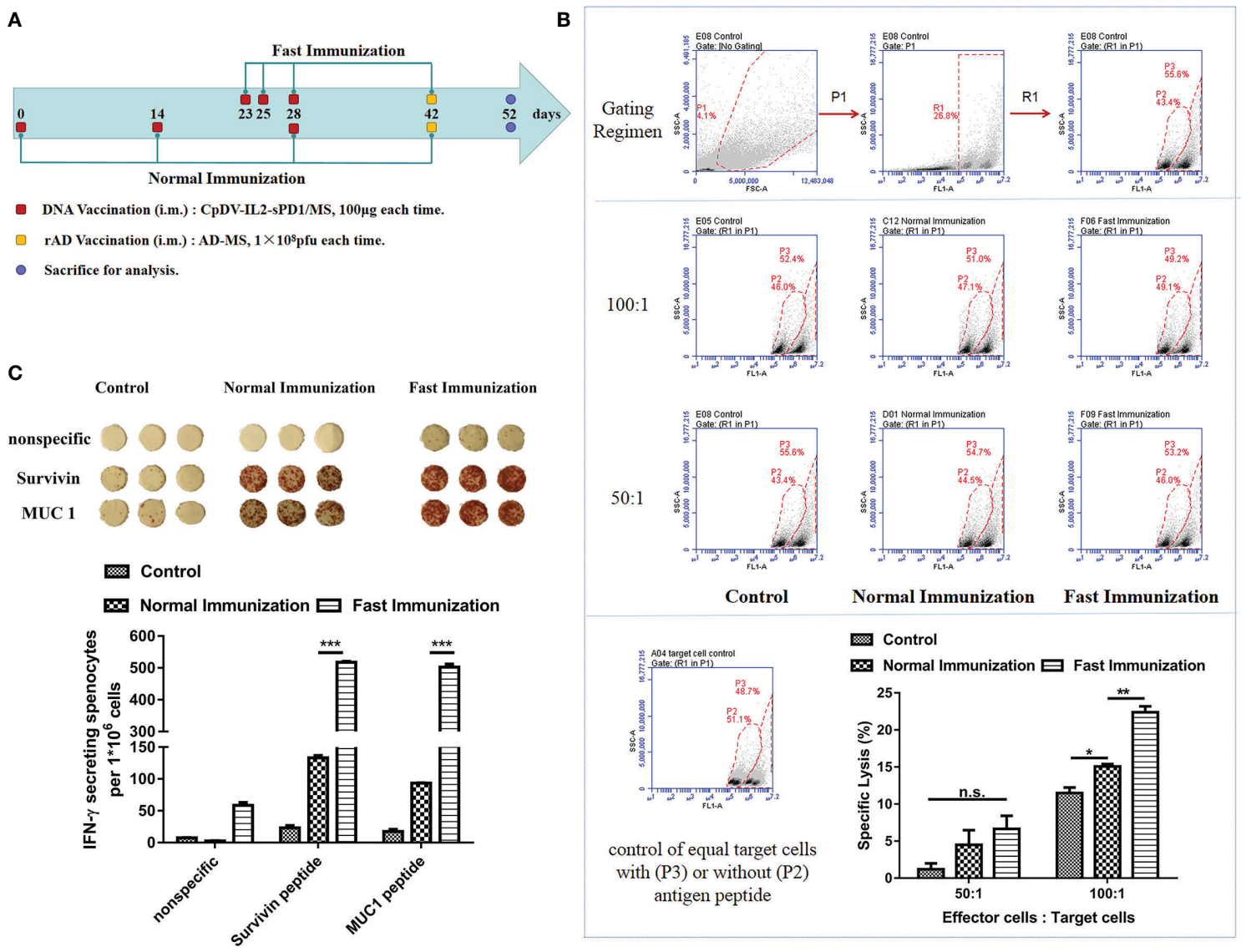

FIGURE 3 | The fast immunization strategy elicited stronger antigen-specific immune responses than did the normal immunization strategy. (A) Immunization regimen in BALB/c mice. Three groups of BALB/c mice (five mice per group) were vaccinated intramuscularly with CpDV-IL2-sPD1/MS (100 $\mu \mathrm{g}$ in 100 $\mu$ l) or PBS (negative control) three times. DNA vaccines were administered at 2-week intervals in the normal immunization group or on days 23, 25 , and 28 in the fast immunization group. Recombinant adenovirus ( $\mathrm{rAd})\left(1 \times 10^{8} \mathrm{pfu}\right.$ in $100 \mu \mathrm{l}$ per mouse) was administered 2 weeks after the last vaccination (day 42$)$ in both groups. PBS was administered under the fast immunization regimen as a negative control. Ten days after rAd vaccination (day 52), all mice were sacrificed to evaluate the immune response. (B) CTL assay. CT26 and CT26-GFP-MS were labeled with carboxyfluorescein diacetate succinimidyl ester (CFSE) of different concentrations (0.5 $\mu \mathrm{M}$ and $5 \mu \mathrm{M}$ ). Splenocytes and a mixture of target cells were incubated at ratios of $50: 1$ and $100: 1$, respectively, for $8 \mathrm{~h}$ at $37^{\circ} \mathrm{C}, 5 \% \mathrm{CO}_{2}$. The percentage of cell death was determined via flow cytometry. Gating for CT26 and CT26-GFP-MS target cells treated with different CFSE concentrations was performed (upper panel). The percentage of CT26-GFP-MS (P3 Gate) and CT26 (P2 Gate) are shown (middle panel). The percentage of specific cytolysis was calculated (lower panel) (C) ELISpot assay. Splenocytes were incubated with hSurvivin peptide (H2-K ${ }^{d}$ sequence: AFLSVKKQF, final concentration: $\left.10 \mu \mathrm{g} / \mathrm{ml}^{2}\right)$ and hMUC1 peptide (H2-K $\mathrm{K}^{\mathrm{d}}$ sequence: APDTRPAPG, final concentration: $10 \mu \mathrm{g} / \mathrm{ml}$ ), and the secretion of IFN- $\gamma$ per million splenocytes (ELISpot assay) was detected. (n.s., $p>0.05$, ${ }^{*} p<0.05$, $\left.{ }^{* \star} \mathrm{p}<0.01,{ }^{* \star *} \mathrm{p}<0.001\right)$.

administered under the fast immunization strategy, for comparison with the $100-\mu \mathrm{g}$ dosage based on the resulting immune response (Figure $\mathbf{4 F}$ ). The CTL assay revealed no significant differences between 100 and $50 \mu \mathrm{g}(p>0.05)$ vaccination. Both the $100-$ and $50-\mu$ g vaccine dosages induced greater CTL-mediated cytolysis than did the $25-\mu \mathrm{g}$ dosage at an E/ $\mathrm{T}$ ratio of 100:1 $(p<0.01$, Figure 4G). ELISpot assay results confirmed no significant differences among the 100-, 50-, and 25$\mu \mathrm{g}$ groups $(p>0.05$, Figure $\mathbf{4 H})$. These results suggested that dosage does not play an important role in the fast vaccination strategy, as opposed to the traditional strategy, wherein the immune response was dose-dependent (Figure S1).

The DNA vaccine dosage had little effect on the efficacy of the fast vaccination strategy as per the data presented in
Figure 4. Triple dosage at once or a lower dose administered on three separate occasions elicited slightly different or similar immune responses. This strongly suggests that the migration of APCs to the injection site played the key role under fast vaccination.

\section{Expansion and Contraction Time Line of CD8 $^{+}$T Cells After Fast Vaccination}

The above-described results highlighted the potential of fast vaccination as an alternative to the currently employed cancer vaccine administration regimens. As a new strategy, the expansion and contraction timeline of effector $\mathrm{CD}^{+} \mathrm{T}$ cells should be elucidated, and it would be useful when this fast DNA vaccination strategy is boosted with $\mathrm{HAD}$ vaccine in the following 
A

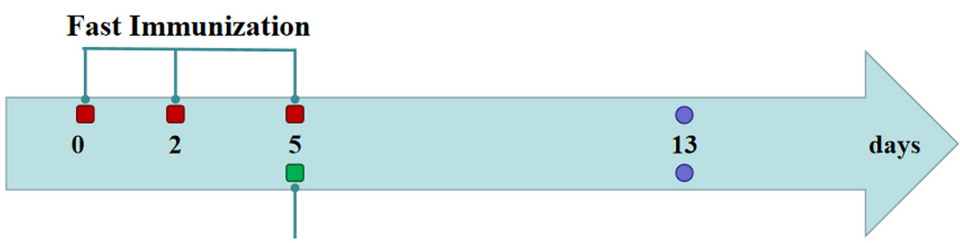

Triple dose

DNA Vaccination (i.m.) : CpDV-IL2-sPD1/MS, 100 $\mu$ g each time.

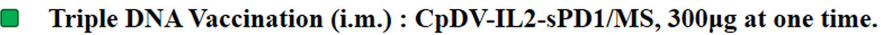

- Sacrifice for analysis.

B

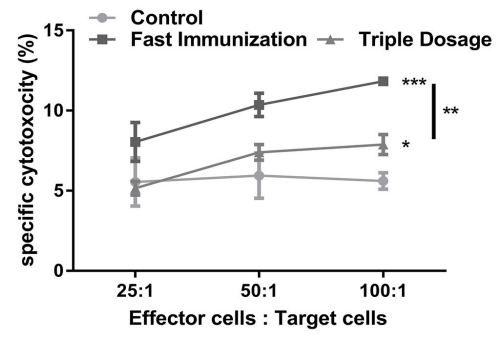

D

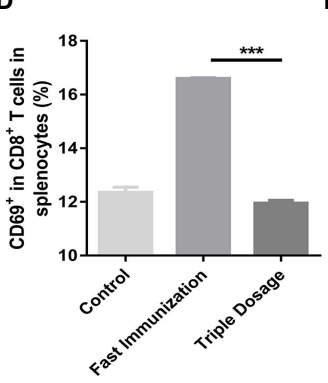

G

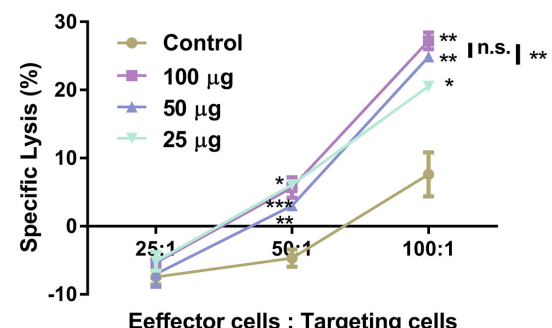

C

E
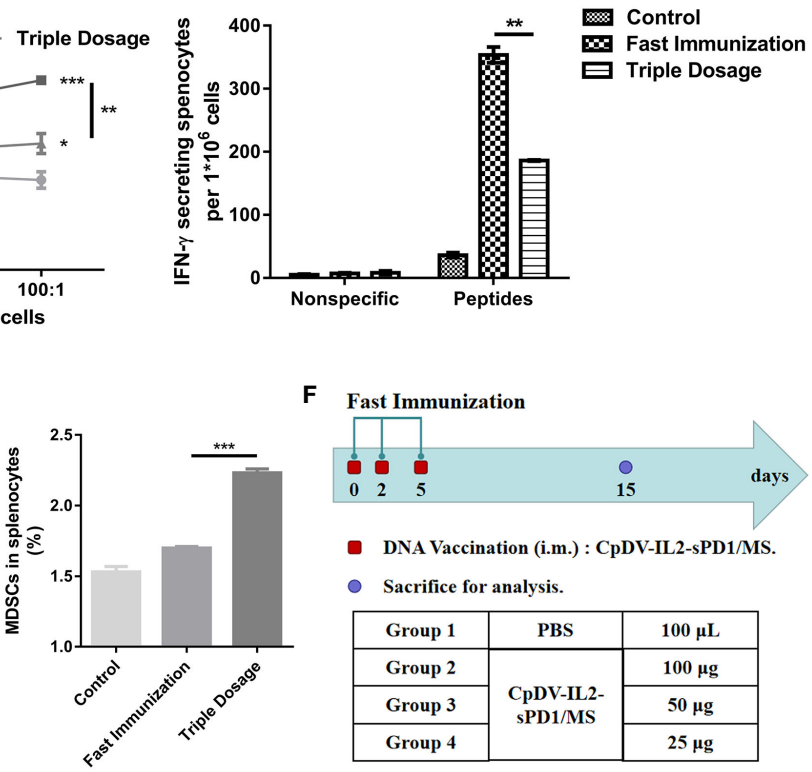

Fast Immunization

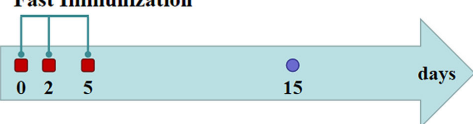

- DNA Vaccination (i.m.) : CpDV-IL2-sPD1/MS.

- Sacrifice for analysis.

\begin{tabular}{|c|c|c|}
\hline Group 1 & PBS & $100 \mu \mathrm{L}$ \\
\hline Group 2 & \multirow{3}{*}{ CPDV-IL2- } & $100 \mu \mathrm{g}$ \\
\cline { 1 - 1 } sPD1/MS & $50 \mu \mathrm{g}$ \\
\cline { 1 - 1 } Group 3 & & $25 \mu \mathrm{g}$ \\
\hline Group 4 & &
\end{tabular}

H

Control

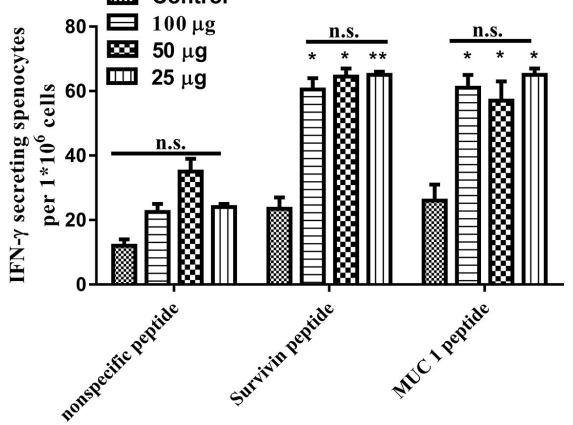

FIGURE 4 | Efficacy of DNA vaccine dosage in the fast immunization strategy. (A) Immunization regimen. In the fast immunization group, BALB/c mice ( $\mathrm{n}=5$ ) were vaccinated with $100 \mu \mathrm{g}$ DNA vaccine on days 0,2 , and 5 . In the triple-dosage group, mice were vaccinated with $300 \mu \mathrm{g}$ DNA vaccine (150 $\mu \mathrm{g}$ in each thigh muscle) once on day 5. All mice were sacrificed on day 13. The splenocytes were separated and analyzed. (B) Cytotoxic T lymphocyte (CTL) assay. The E/T ratio was $25: 1$, 50:1, and 100:1, respectively. (C) ELISpot assay. Splenocytes were stimulated with peptides (survivin H2-K ${ }^{d}$ sequence: AFLSVKKQF, final concentration: $10 \mu$ g/ml; MUC1 H2-Kd sequence: APDTRPAPG, final concentration: $10 \mu \mathrm{g} / \mathrm{ml}$ ). (D) Activation of CD8 ${ }^{+} \mathrm{T}^{\mathrm{d}}$ cells. The percentage of CD69 ${ }^{+}-\mathrm{PE}$ cells was determined by flow cytometry (FACS) with gating for $\mathrm{CD}^{+} \mathrm{FITC} / \mathrm{CD} 8^{+}$antigen-presenting cells. (E) Myeloid-derived suppressor cells (MDSCs) in lymphocytes. The percentage of MDSCs, CD11b-PE/Gr-1 APC/Ly-6G FITC, was detected using FACS. (F) Twenty BALB/c mice ( $n=5)$ were divided into four groups. Vaccine doses included 25, 50 , and $100 \mu \mathrm{g}$ at each time point in the respective treatment group. The vaccination and intervals were as for the fast immunization strategy in (A). (G) CTL assay. (H) ELISpot assay. $\left({ }^{\star} p<0.05,{ }^{* *} p<0.01,{ }^{\star * *} p<0.001\right.$, n.s., $\left.p>0.05\right)$. 
research. C57BL/6 mice were inoculated with Lewis-GFP-MS, vaccinated, and then sacrificed for analysis during the period of day 0 and day 14 after the last DNA vaccination (Figure 5A). To comprehensively reflect the antitumor effect, the tumor size was evaluated (Figure 5B). Three mice per group were sacrificed at each time point, and their tumors were dissected and weighed. When vaccines were administered under the fast immunization strategy, tumor growth was suppressed by $83.6 \%(p<0.05$, day 3), $72.86 \%$ ( $p<0.05$, day 7$), 71.10 \%$ ( $p<0.01$, day 10$)$, and $46.34 \%$ ( $p>0.05$, day 14) (Figure 5B). The function of antigenspecific IFN- $\gamma$ secretion and cytolysis were also analyzed by ELISpot assay and CTL assay. ELISpot (Figure 5C) and CTL (Figure 5D) assays indicated that fast vaccination induced an effective immune response on the third day after the last vaccination, which persisted to the 10th day.
Tumor-infiltrating $\mathrm{CD} 8^{+} \mathrm{T}$ cells are thought to be the direct executor of killing tumor cells. Hence, we also analyzed the activated $\mathrm{CD}^{+} \mathrm{T}$ cells $\left(\mathrm{CD} 8^{+} / \mathrm{CD} 9^{+}\right.$cells) in both spleen (Figure 5E) and tumor tissue (Figure 5F) by FACS. At 7 and 14 days after the last vaccination, more $\mathrm{CD} 8^{+} / \mathrm{CD} 69^{+}$cells were observed in both the spleen and tumors in the vaccine group than in the PBS group $(p<0.01$, Figures 5E, F). Interestingly, $\mathrm{CD}^{+} / \mathrm{CD} 9^{+}$cells showed an obvious reduction in tumor tissue at day 14 compared with day 7 in both groups $(p<$ 0.001 , Figure 5F).

\section{Fast Vaccination Suppressed Larger Tumors to a Greater Extent}

We sought to determine whether the faster and more potent immune response elicited under the fast immunization strategy

A Fast Immunization

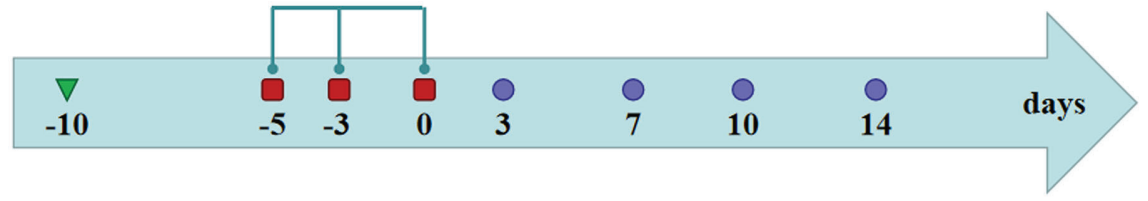

$\triangle$ Tumor Inoculation : Lewis-GFP-MS, $1.4 \times 10^{5}$ cells per mouse.

DNA Vaccination (i.m.) : CpDV-IL2-sPD1/MS, 100 $\mu$ g each time.

- Sacrifice for analysis.
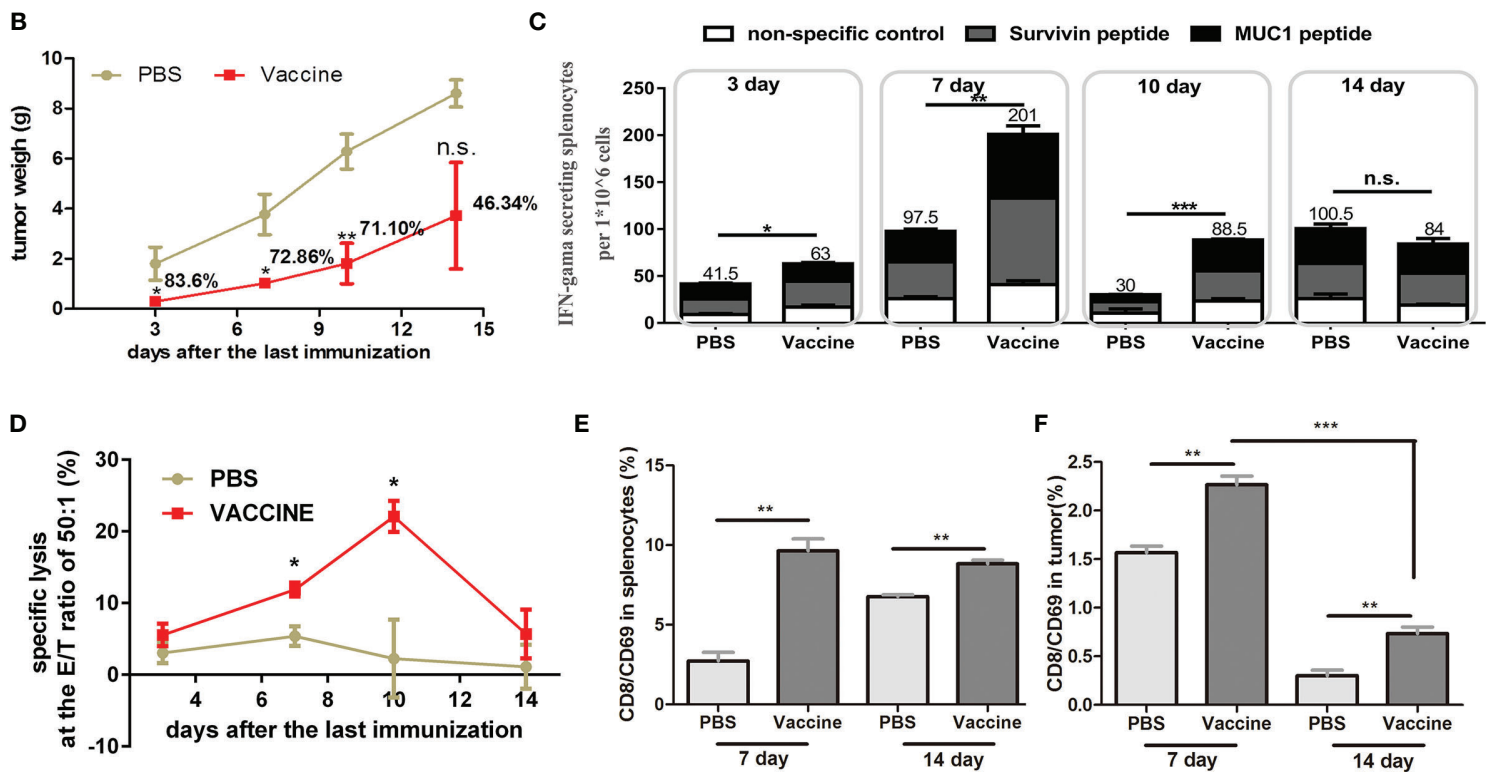

FIGURE 5 | Anti-tumor effect and temporal immune response to the DNA vaccine in the fast immunization strategy. (A) Immunization regimen in tumor-bearing mice. Twenty-four C57BL/6 mice were separated into a PBS group $(n=12)$ and a vaccine group $(n=12)$, and $1.4 \times 10^{5}$ Lewis-GFP-MS cells were subcutaneously injected into mice. Five days later, tumor volume reached approximately $50 \mathrm{~mm}^{3}$, and mice were vaccinated on days -5 , -3 , and 0 with $100 \mu \mathrm{g}$ of CpDV-IL2-sPD1/ MS (intramuscularly injected). Three mice per group were sacrificed on days 3, 7, 10, and 14. (B) Tumor weight. Tumor tissues were dissected and weighed. (C) ELISpot assay. Splenocytes were stimulated with peptides (survivin H2- $\mathrm{D}^{\mathrm{b}}$ sequence: STFKNWPFL, final concentration: $10 \mu \mathrm{g} / \mathrm{ml}$; MUC1 H2-D ${ }^{\mathrm{b}}$ sequence: SAPDTRPAP, final concentration: $10 \mu \mathrm{g} / \mathrm{ml}$ ). (D) Cytotoxic T lymphocyte (CTL) assay. Lewis and Lewis-GFP-MS cells were labeled with 0.5 and $5 \mu \mathrm{M}$ carboxyfluorescein diacetate succinimidyl ester (CFSE), and mixed at a ratio of 1:1. The mixed Lewis and Lewis-GFP-MS cells were used as target cells to analyze the antigen-specific cytolytic ability of splenocytes via flow cytometry. Effector $\mathrm{CD} 8^{+} / \mathrm{CD} 69^{+}$cells and suppressor cells were separated from splenocytes (E) and tumor tissue (F). $\left({ }^{*} p<0.05,{ }^{* *} p<0.01,{ }^{* \star *} p<0.001\right.$, n.s., $\left.p>0.05\right)$. 
would result in enhanced antitumor immunity. Further, due to the time-consuming immune response, the normal vaccination strategy has to initiate the treatment 1 day after tumor incubation in our previous research $(29,30,32)$. In this part, the fast DNA vaccination strategy was challenged with initiating treatment till tumor mass was about $50-100 \mathrm{~mm}^{3}$. The first DNA vaccine was vaccinated 7 days later in the fast vaccination strategy group than that in the normal vaccination strategy group. The antitumor effect and survival time were analyzed (Figure 6). $\mathrm{C} 57 \mathrm{BL} / 6$ mice in the normal vaccination group received the DNA vaccine on day 1 after tumor cell inoculation. Mice in the fast vaccination group received the DNA vaccine on day 8 , when tumor volume reached approximately $50 \mathrm{~mm}^{3}$ (Figure 6A). Tumor size was suppressed by $47.82 \%$ in the fast vaccination group relative to that in the normal immunization group (52.68\%). Even though the vaccine was administered 7 days later in the fast immunization group than in the normal immunization group, no significant difference in tumor growth suppression was observed between the two groups $(p>0.05)$ (Figure 6B). Moreover, the survival time of mice was prolonged by $47.45 \%$ in the fast immunization group ( $p<0.001$, vs. control group; $\mathrm{p}<0.05$ vs. normal group), and the survival time of mice was prolonged by $27.06 \%$ in the normal group ( $p<0.001$, vs. control group, Figure 6C). These data demonstrate that the fast immunization strategy induced stronger antitumor effects than the normal strategy did, even when vaccines were administered at a later stage.

\section{Safety}

The safety evaluations tests of the fast DNA vaccination strategy was entrusted to Shandong Xinbo Pharmaceutical R\&D, LED. Long-term toxicity test and acute toxicity tests were carried out on Balb/c mice and cynomolgus monkeys. These results showed that no obvious abnormality in weight gain was found in the $\mathrm{Balb} / \mathrm{c}$ mice after treatment via rapid DNA vaccination strategy, and the major organs (such as heart, liver, kidney, lung, and spleen) of Balb/c mice and cynomolgus monkey showed no toxic effects (data not shown).

\section{DISCUSSION}

We developed a fast vaccination strategy, wherein a cancer DNA vaccine was intramuscularly administered on days 0,2 , and 5 . This approach elicited a stronger immune response and exhibited enhanced antitumor efficacy. We also elucidated the potential mechanism underlying the effects of the fast vaccination strategy and observed an upregulation of CCL3, CCL5, and CCL19 as well as the recruitment of CD11c ${ }^{+}$cells to the injection site. The timing of booster DNA vaccination was

A

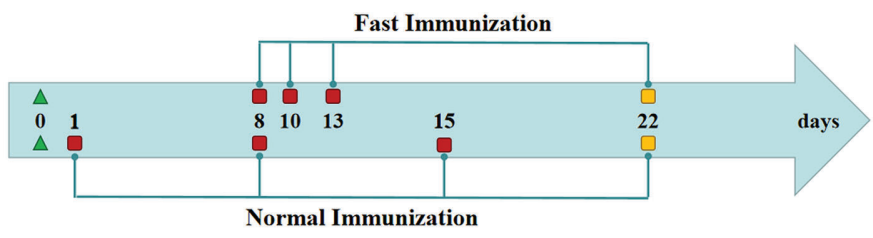

$\triangle$ Tumor Inoculation : Lewis-GFP-MS, $1.4 \times 10^{5}$ cells per mouse.

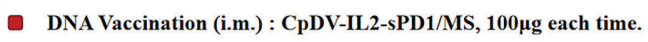

$\square$ rAD Vaccination (i.m.) : AD-MS, $1 \times 10^{8}$ pfu each time.

B

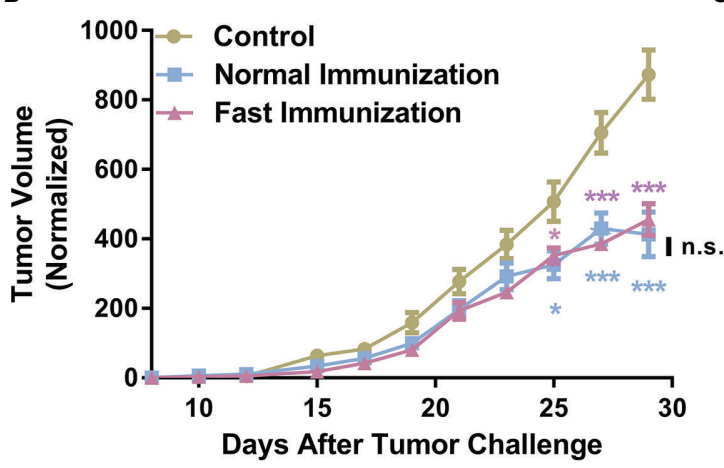

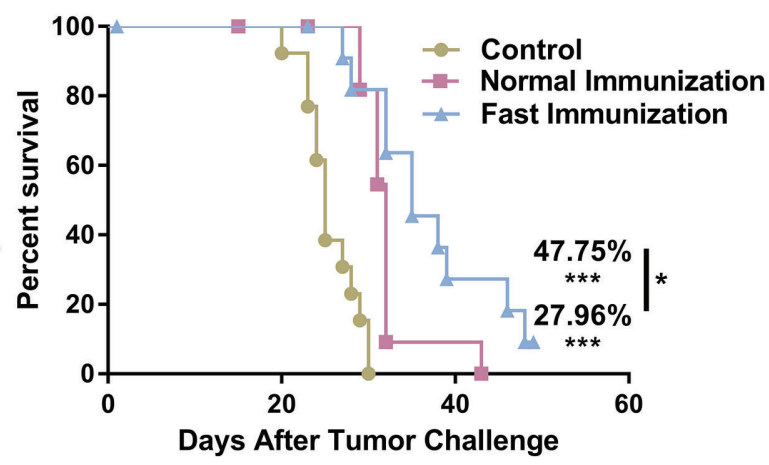

FIGURE 6 | Improved antitumor effect of the DNA vaccine under the fast immunization strategy, even in larger tumors. (A) Tumor incubation and vaccination strategy regimen. Lewis-GFP-MS cells $\left(1.4 \times 10^{5}\right)$ were injected subcutaneously into the right hind flanks of C57BL/6 mice. In the normal immunization group $(\mathrm{n}=$ 12), the DNA vaccine was administered 1 day later and at 1 -week intervals thereafter. In the fast immunization group ( $n=12$ ), the DNA vaccine was administered on day 8 , when the tumor volume reached approximately $50 \mathrm{~mm}^{3}$. The following two vaccinations were administered on days 10 and 13 : $1 \times 10^{8}$ pfu rAd on day 22 in both groups and PBS in control group mice $(n=13)$. (B) Tumor growth curves. Tumor volume measurements were taken beginning from day 8 after tumor cell inoculation. (C) Survival analysis was conducted by recording the death of tumor-bearing mice $\left({ }^{\star} p<0.05,{ }^{\star \star \star} p<0.001\right.$, n.s., $\left.p>0.05\right)$. 
based on that of $\mathrm{CD} 11 \mathrm{c}^{+}$cell accumulation at the injection site. The presence of these cells most probably facilitated increased antigen presentation or cross-presentation. Several recent studies have reported the recruitment of DCs to the inflammation site caused by adjuvants or wounds, with these APCs playing a pivotal role in the initiation of subsequent immune responses (27-30). The fast vaccination strategy likely stimulated CD11c ${ }^{+}$ cell migration to increase the uptake of vaccine DNA as well as direct antigen uptake.

Our DNA vaccine was administrated intramuscularly instead of subcutaneously and elicited a stronger antitumor immune response than did the conventional 2-week-interval strategy. We analyzed the antitumor efficacy of fast vaccination in C57BL/6 mice subcutaneously inoculated with Lewis cells. We previously applied this strategy in a mouse model of breast cancer (4T1 breast cancer cell line, BALB/c mice) (42) as well as a pancreatic cancer C57BL/6 mouse model (Panc02 pancreatic cancer cell line, unpublished data). In all three cancer models, including both $\mathrm{C} 57 \mathrm{BL} / 6$ and $\mathrm{BALB} / \mathrm{c}$ mouse strains, fast vaccination showed consistent results, indicating that its beneficial effects are not strain-dependent and highlighting its potential as a superior alternative to conventional vaccination regimens.

Immunogens are a critical factor for immune response induction. However, according to our results, the amount of antigens did not influence the strength of the immune response elicited by the fast vaccination strategy. Under the fast vaccination regimen, the $25-\mu \mathrm{g}$ DNA vaccine induced a similar immune response to that following the $100-\mu \mathrm{g}$ DNA vaccine administration, which contrasted the dose-dependent effect observed under the normal vaccination strategy. Further, we administered a triple-dosage DNA vaccine to verify the relationship between antigen expression and the fast vaccination strategy. Our results indicated that the efficacy of fast vaccination was not dependent on the DNA vaccine dose. This observation is in agreement with the report by Schumacher et al., who suggested that antigen expression is not the key factor underlying the efficacy of fast vaccination via intramuscular injection (7). We attribute this enhanced immune response to the accumulation of $\mathrm{CD} 11 \mathrm{c}^{+} \mathrm{APCs}$ at the injection site and the immunoadjuvants in our vaccine. In future research, the role of immunoadjuvants in upregulating chemokines and recruiting APCs should be explored in greater detail.

Heterologous prime-boost immunization is used to enhance the immune response induced by DNA vaccines. In our previous research, we found that rAd boost enhanced the efficacy of CpDVIL2-sPD1/MS under the normal immunization strategy. Hence, we applied the rAd boost under fast immunization and compared it with the normal strategy. We also analyzed the cell subtypes implicated in the immune response after fast vaccination.

Importantly, the fast vaccination strategy not only represents a time-saving option but also exhibited antitumor efficacy following vaccine administration at a later point of disease progression as opposed to the traditional strategy. We attribute this outcome to the shorter vaccination regimen and the more rapid peaking of the immune response. Research has shown that tumors establish a tumor-associated microenvironment as the disease progresses in order to evade immune surveillance, chemotherapy, and radiotherapy (43-45). Therefore, earlier immune response induction allows for greater tumor cell killing.

Additionally, the rapid vaccination strategy has the advantage in combined therapies. Due to the heterogeneity of cancer, a single treatment is hard to wipe out all the tumor cells. Therefore, cancer vaccines are always used together with chemotherapy or radiotherapy. It is difficult to determine the effects of these chemotherapy or radiotherapy on immunotherapy during combination treatment. Sometimes, chemotherapy or radiotherapy killed the suppressed immune cells, and sometimes they killed effector immune cells. The fast vaccination strategy could be applied between the courses of chemotherapy and avoiding decreasing the effector immune response.

Moreover, according to the safety evaluations tests, the rapid DNA vaccination strategy showed an excellent safety. Chen et al. found that the immune system, including IL-22, was closely related to the recovery of kidney and liver (46-48). These results inspire us that DNA cancer vaccine is an effect cancer treatment with good safety.

In the current study, the cancer DNA vaccine CpDV-IL2sPD1/MS was administered under a fast vaccination strategy and demonstrated enhanced efficacy relative to the conventional vaccination strategy. Future research should explore this approach with other vaccines and elucidate the molecular mechanism of DC recruitment within muscle tissue.

\section{DATA AVAILABILITY STATEMENT}

The original contributions presented in the study are included in the article/Supplementary Material. Further inquiries can be directed to the corresponding authors.

\section{ETHICS STATEMENT}

The animal study was reviewed and approved by the Ethical Committee for the Use of Laboratory Animals at Jilin University.

\section{AUTHOR CONTRIBUTIONS}

CL: conceptualization, data curation, formal analysis, investigation, visualization, writing-original draft, and funding acquisition. $\mathrm{XC}$ and YW: conceptualization and formal analysis. QG, YX, FG, JG, LD, and YZ: investigation. HW, BY, and JW: methodology. HZ: conceptualization, funding acquisition, project administration, supervision, writing-review, and editing. XY: project administration, supervision, and validation. WK: funding acquisition, project administration, and resources. All authors contributed to the article and approved the submitted version.

\section{FUNDING}

This study was supported by Projects of Science and Technology Department of Jilin Province, China [no. 20210101249JC], Key R \& D Projects of Science and Technology Department of Jilin Province, 
China [no. 20180201001YY], Major Projects of Science and Technology Innovation in Changchun City, China [no. 17YJ002], the Specialized Research Fund for the National Natural Science Foundation of China [no. 31300765], the Jilin Province Science and Technology Development Program, China [no. 20160519018JH], International Cooperation Projects of Science and Technology Department of Jilin Province, China [no. 20190701061GH], and Youth Learner Fund for the National Natural Science Foundation of China [no. 81601445]. We declare all sources of funding received for the research being submitted.

\section{ACKNOWLEDGMENTS}

We thank Editage for the valuable suggestions and editorial help.

\section{SUPPLEMENTARY MATERIAL}

The Supplementary Material for this article can be found online at: https://www.frontiersin.org/articles/10.3389/fonc.2021. 752444/full\#supplementary-material

Supplementary Figure 1 | Immune response induced by the DNA vaccine under the normal vaccination strategy depends on the vaccine dosage. (A) Immunization regimen. Twenty BALB/c mice were divided into four groups $(n=5)$. DNA vaccine doses included 25,50 , and $100 \mu \mathrm{g}$ in the respective groups. Vaccines were administered intramuscularly three times at two-week intervals. Recombinant adenovirus ( $\mathrm{rAd})\left(1 \times 10^{8} \mathrm{pfu}\right.$ in $100 \mu \mathrm{l}$ per mouse) was administered two weeks after administration of the last DNA vaccine dose (B) ELISpot assay. Ten days after rAd vaccination, all mice were sacrificed to perform the ELISpot assay. Splenocytes were incubated with hSurvivin peptide $\left(\mathrm{H}_{2}-\mathrm{K}^{\mathrm{d}}\right.$ sequence: AFLSVKKQF, final concentration: $10 \mu \mathrm{g} / \mathrm{mL}$ ) and hMUC1 peptide (H2-K $\mathrm{K}^{\mathrm{d}}$ sequence: APDTRPAPG, final concentration: $10 \mu \mathrm{g} / \mathrm{mL}$ ), and the secretion of IFN- $\gamma$ per million splenocytes (ELISpot assay) was determined. (n.s. $p>0.05,{ }^{*} p<0.05$, ${ }^{\star *} p<0.01,{ }^{\star \star *} p<0.001$ ).

\section{REFERENCES}

1. Lopes A, Vandermeulen G, Préat V. Cancer DNA Vaccines: Current Preclinical and Clinical Developments and Future Perspectives. J Exp Clin Cancer Res (2019) 38(1):146. doi: 10.1186/s13046-019-1154-7

2. Chen YL, Chang MC, Chiang YC, Lin HW, Sun NY, Chen CA, et al. Immuno-Modulators Enhance Antigen-Specific Immunity and Anti-Tumor Effects of Mesothelin-Specific Chimeric DNA Vaccine Through Promoting DC Maturation. Cancer Lett (2018) 425:152-63. doi: 10.1016/j.canlet.2018. 03.032

3. Mei Y, Zhao L, Liu Y, Gong H, Song Y, Lei L, et al. Combining DNA Vaccine and AIDA-1 in Attenuated Salmonella Activates Tumor-Specific CD4+ and CD8+ T-Cell Responses. Cancer Immunol Res (2017) 5(6):503-14. doi: 10.1158/2326-6066.CIR-16-0240-T

4. Tiptiri-Kourpeti A, Spyridopoulou K, Pappa A, Chlichlia K. DNA Vaccines to Attack Cancer: Strategies for Improving Immunogenicity and Efficacy. Pharmacol Ther (2016) 165:32-49. doi: 10.1016/j.pharmthera.2016. 05.004

5. McNeel DG, Eickhoff JC, Johnson LE, Roth AR, Perk TG, Fong L, et al. Phase II Trial of a DNA Vaccine Encoding Prostatic Acid Phosphatase (pTVG-HP [MVI-816]) in Patients With Progressive, Nonmetastatic, CastrationSensitive Prostate Cancer. J Clin Oncol (2019) 37(36):3507-17. doi: 10.1200/JCO.19.01701

6. Johnson LE, Frye TP, Arnot AR, Marquette C, Couture LA, GendronFitzpatrick A, et al. Safety and Immunological Efficacy of a Prostate Cancer Plasmid DNA Vaccine Encoding Prostatic Acid Phosphatase (PAP). Vaccine (2006) 24(3):293-303. doi: 10.1016/j.vaccine.2005.07.074

7. Bins AD, Jorritsma A, Wolkers MC, Hung CF, Wu TC, Schumacher TN, et al. A Rapid and Potent DNA Vaccination Strategy Defined by In Vivo Monitoring of Antigen Expression. Nat Med (2005) 11(8):899-904. doi: $10.1038 / \mathrm{nm} 1264$

8. Lopes A, Vanvarenberg K, Kos Š, Lucas S, Colau D, Van den Eynde B, et al. Combination of Immune Checkpoint Blockade With DNA Cancer Vaccine Induces Potent Antitumor Immunity Against P815 Mastocytoma. Sci Rep (2018) 8(1):15732. doi: 10.1038/s41598-018-33933-7

9. Aravanis AM, Lee M, Klausner RD. Next-Generation Sequencing of Circulating Tumor DNA for Early Cancer Detection. Cell (2017) 168 (4):571-4. doi: 10.1016/j.cell.2017.01.030

10. Ott PA, Hu Z, Keskin DB, Shukla SA, Sun J, Bozym DJ, et al. An Immunogenic Personal Neoantigen Vaccine for Patients With Melanoma. Nature (2017) 547(7662):217-21. doi: 10.1038/nature22991

11. Rezaei T, Davoudian E, Khalili S, Amini M, Hejazi M, de la Guardia M, et al. Strategies in DNA Vaccine for Melanoma Cancer. Pigment Cell Melanoma Res (2021) 34(5):869-91. doi: 10.1111/pcmr.12933

12. Zahm CD, Colluru VT, McNeel DG. DNA Vaccines for Prostate Cancer. Pharmacol Ther (2017) 174:27-42. doi: 10.1016/j.pharmthera.2017.02.016

13. Johnson LE, Olson BM, McNeel DG. Pretreatment Antigen-Specific Immunity and Regulation - Association With Subsequent Immune Response to Anti-Tumor DNA Vaccination. J Immunother Cancer (2017) 5 (1):56. doi: 10.1186/s40425-017-0260-3

14. Becker JT, Olson BM, Johnson LE, Davies JG, Dunphy EJ, McNeel DG. DNA Vaccine Encoding Prostatic Acid Phosphatase (PAP) Elicits Long-Term TCell Responses in Patients With Recurrent Prostate Cancer. J Immunother (2010) 33(6):639-47. doi: 10.1097/CJI.0b013e3181dda23e

15. Irvine DJ, Aung A, Silva M. Controlling Timing and Location in Vaccines. Adv Drug Delivery Rev (2020) 158:91-115. doi: 10.1016/j.addr.2020.06.019

16. Duperret EK, Perales-Puchalt A, Stoltz R, G HH, Mandloi N, Barlow J, et al. A Synthetic DNA, Multi-Neoantigen Vaccine Drives Predominately MHC Class I CD8+ T-Cell Responses, Impacting Tumor Challenge. Cancer Immunol Res (2019) 7(2):174-82. doi: 10.1158/2326-6066.CIR-18-0283

17. Li L, Petrovsky N. Molecular Mechanisms for Enhanced DNA Vaccine Immunogenicity. Expert Rev Vaccines (2016) 15(3):313-29. doi: 10.1586/ 14760584.2016.1124762

18. Wolff JA, Malone RW, Williams P, Chong W, Acsadi G, Jani A, et al. Direct Gene Transfer Into Mouse Muscle In Vivo. Science (1990) 247(4949 Pt 1):1465-8. doi: 10.1126/science.1690918

19. Wolff JA, Budker V. The Mechanism of Naked DNA Uptake and Expression. Adv Genet (2005) 54:3-20. doi: 10.1016/S0065-2660(05)54001-X

20. Jorritsma SHT, Gowans EJ, Grubor-Bauk B, Wijesundara DK. Delivery Methods to Increase Cellular Uptake and Immunogenicity of DNA Vaccines. Vaccine (2016) 34(46):5488-94. doi: 10.1016/j.vaccine.2016.09.062

21. Peachman KK, Rao M, Alving CR. Immunization With DNA Through the Skin. Methods (2003) 31(3):232-42. doi: 10.1016/S1046-2023(03)00137-3

22. Balan S, Saxena M, Bhardwaj N. Dendritic Cell Subsets and Locations. Int Rev Cell Mol Biol (2019) 348:1-68. doi: 10.1016/bs.ircmb.2019.07.004

23. Fu C, Jiang A. Dendritic Cells and CD8 T Cell Immunity in Tumor Microenvironment. Front Immunol (2018) 9:3059. doi: 10.3389/ fimmu.2018.03059

24. Elnekave M, Furmanov K, Nudel I, Arizon M, Clausen BE, Hovav AH. Directly Transfected Langerin+ Dermal Dendritic Cells Potentiate CD8+ T Cell Responses Following Intradermal Plasmid DNA Immunization. J Immunol (2010) 185(6):3463-71. doi: 10.4049/jimmunol.1001825

25. Sánchez-Paulete AR, Teijeira A, Cueto FJ, Garasa S, Pérez-Gracia JL, SánchezArráez A, et al. Antigen Cross-Presentation and T-Cell Cross-Priming in Cancer Immunology and Immunotherapy. Ann Oncol (2017) 28(suppl_12): xii44-55. doi: 10.1093/annonc/mdx237

26. Tiberio L, Del Prete A, Schioppa T, Sozio F, Bosisio D, Sozzani S. Chemokine and Chemotactic Signals in Dendritic Cell Migration. Cell Mol Immunol (2018) 15(4):346-52. doi: 10.1038/s41423-018-0005-3

27. Corrales L, Matson V, Flood B, Spranger S, Gajewski TF. Innate Immune Signaling and Regulation in Cancer Immunotherapy. Cell Res (2017) 27 (1):96-108. doi: 10.1038/cr.2016.149 
28. Mitchell D, Olive C. Regulation of Toll-Like Receptor-Induced Chemokine Production in Murine Dendritic Cells by Mitogen-Activated Protein Kinases. Mol Immunol (2010) 47(11-12):2065-73. doi: 10.1016/j.molimm.2010.04.004

29. O'Hagan DT, Ott GS, De Gregorio E, Seubert A. The Mechanism of Action of MF59 - an Innately Attractive Adjuvant Formulation. Vaccine (2012) 30 (29):4341-8. doi: 10.1016/j.vaccine.2011.09.061

30. Ho NI, Huis In 't Veld LGM, Raaijmakers TK, Adema GJ. Adjuvants Enhancing Cross-Presentation by Dendritic Cells: The Key to More Effective Vaccines? Front Immunol (2018) 9:2874. doi: 10.3389/ fimmu.2018.02874

31. Liu C, Lu Z, Xie Y, Guo Q, Geng F, Sun B, et al. Soluble PD-1-Based Vaccine Targeting MUC1 VNTR and Survivin Improves Anti-Tumor Effect. Immunol Lett (2018) 200:33-42. doi: 10.1016/j.imlet.2018.06.004

32. Liu C, Xie Y, Sun B, Geng F, Zhang F, Guo Q, et al. MUC1- and SurvivinBased DNA Vaccine Combining Immunoadjuvants CpG and Interleukin-2 in a Bicistronic Expression Plasmid Generates Specific Immune Responses and Antitumour Effects in a Murine Colorectal Carcinoma Model. Scand J Immunol (2018) 87(2):63-72. doi: 10.1111/sji.12633

33. Zhang H, Wang Y, Liu C, Zhang L, Xia Q, Zhang Y, et al. DNA and Adenovirus Tumor Vaccine Expressing Truncated Survivin Generates Specific Immune Responses and Anti-Tumor Effects in a Murine Melanoma Model. Cancer Immunol Immunother (2012) 61(10):1857-67. doi: 10.1007/ s00262-012-1296-3

34. Du B, Waxman DJ. Medium Dose Intermittent Cyclophosphamide Induces Immunogenic Cell Death and Cancer Cell Autonomous Type I Interferon Production in Glioma Models. Cancer Lett (2020) 470:170-80. doi: 10.1016/ j.canlet.2019.11.025

35. Wu J, Waxman DJ. Metronomic Cyclophosphamide Schedule-Dependence of Innate Immune Cell Recruitment and Tumor Regression in an Implanted Glioma Model. Cancer Lett (2014) 353(2):272-80. doi: 10.1016/ j.canlet.2014.07.033

36. Geng F, Guo J, Guo QQ, Xie Y, Dong L, Zhou Y, et al. A DNA Vaccine Expressing an Optimized Secreted Fap $\alpha$ Induces Enhanced Anti-Tumor Activity by Altering the Tumor Microenvironment in a Murine Model of Breast Cancer. Vaccine (2019) 37(31):4382-91. doi: 10.1016/j.vaccine.2019.06.012

37. Guo Q, Wang L, Xu P, Geng F, Guo J, Dong L, et al. Heterologous PrimeBoost Immunization Co-Targeting Dual Antigens Inhibit Tumor Growth and Relapse. Oncoimmunology (2020) 9(1):1841392. doi: 10.1080/2162402X.2020. 1841392

38. Cossarizza A, Chang HD, Radbruch A, Acs A, Adam D, Adam-Klages S, et al. Guidelines for the Use of Flow Cytometry and Cell Sorting in Immunological Studies (Second Edition). Eur J Immunol (2019) 49(10):1457-973. doi: 10.1002/eji.201970107

39. Korbecki J, Grochans S, Gutowska I, Barczak K, Baranowska-Bosiacka I. CC Chemokines in a Tumor: A Review of Pro-Cancer and Anti-Cancer Properties of Receptors CCR5, CCR6, CCR7, CCR8, CCR9, and CCR10 Ligands. Int J Mol Sci (2020) 21(20):7619. doi: 10.3390/ijms21207619

40. Van Beusecum JP, Barbaro NR, McDowell Z, Aden LA, Xiao L, Pandey AK, et al. High Salt Activates CD11c ${ }^{+}$Antigen-Presenting Cells via SGK (Serum
Glucocorticoid Kinase) 1 to Promote Renal Inflammation and Salt-Sensitive Hypertension. Hypertension (2019) 74(3):555-63. doi: 10.1161/ HYPERTENSIONAHA.119.12761

41. Sandor AM, Lindsay RS, Dyjack N, Whitesell JC, Rios C, Bradley BJ, et al. CD11c+ Cells Are Gatekeepers for Lymphocyte Trafficking to Infiltrated Islets During Type 1 Diabetes. Front Immunol (2019) 10:99. doi: 10.3389/ fimmu.2019.00099

42. Geng F, Bao X, Dong L, Guo QQ, Guo J, Xie Y, et al. Doxorubicin Pretreatment Enhances Fap $\alpha /$ Survivin Co-Targeting DNA Vaccine AntiTumor Activity Primarily Through Decreasing Peripheral MDSCs in the 4T1 Murine Breast Cancer Model. Oncoimmunology (2020) 9(1):1747350. doi: 10.1080/2162402X.2020.1747350

43. Wu T, Dai Y. Tumor Microenvironment and Therapeutic Response. Cancer Lett (2017) 387:61-8. doi: 10.1016/j.canlet.2016.01.043

44. Hirata E, Sahai E. Tumor Microenvironment and Differential Responses to Therapy. Cold Spring Harb Perspect Med (2017) 7(7):a026781. doi: 10.1101/ cshperspect.a026781

45. Frankel T, Lanfranca MP, Zou W. The Role of Tumor Microenvironment in Cancer Immunotherapy. Adv Exp Med Biol (2017) 1036:51-64. doi: 10.1007/ 978-3-319-67577-0_4

46. Chen W, Zhang X, Fan J, Zai W, Luan J, Li Y, et al. Tethering Interleukin-22 to Apolipoprotein A-I Ameliorates Mice From Acetaminophen-Induced Liver Injury. Theranostics (2017) 7(17):4135-48. doi: 10.7150/thno.20955

47. Chen W, Shen Y, Fan J, Zeng X, Zhang X, Luan J, et al. IL-22-Mediated Renal Metabolic Reprogramming via PFKFB3 to Treat Kidney Injury. Clin Transl Med (2021) 11(2):e324. doi: 10.1002/ctm2.324

48. Chen W, Zai W, Fan J, Zhang X, Zeng X, Luan J, et al. Interleukin-22 Drives a Metabolic Adaptive Reprogramming to Maintain Mitochondrial Fitness and Treat Liver Injury. Theranostics (2020) 10(13):5879-94. doi: 10.7150/ thno.43894

Conflict of Interest: The authors declare that the research was conducted in the absence of any commercial or financial relationships that could be construed as a potential conflict of interest.

Publisher's Note: All claims expressed in this article are solely those of the authors and do not necessarily represent those of their affiliated organizations, or those of the publisher, the editors and the reviewers. Any product that may be evaluated in this article, or claim that may be made by its manufacturer, is not guaranteed or endorsed by the publisher.

Copyright (C) 2021 Liu, Cong, Wang, Guo, Xie, Geng, Guo, Dong, Zhou, Wu, Yu, Wu, Zhang, Yu and Kong. This is an open-access article distributed under the terms of the Creative Commons Attribution License (CC BY). The use, distribution or reproduction in other forums is permitted, provided the original author(s) and the copyright owner(s) are credited and that the original publication in this journal is cited, in accordance with accepted academic practice. No use, distribution or reproduction is permitted which does not comply with these terms. 